\title{
Differential modulation of hepatic very low-density lipoprotein secretion by triacylglycerol-rich lipoproteins derived from different oleic-acid rich dietary oils
}

\author{
Javier S. Perona ${ }^{1}$, Michael Avella ${ }^{2}$, Kathleen M. Botham ${ }^{2}$ and Valentina Ruiz-Gutierrez ${ }^{1}$ * \\ ${ }^{1}$ Instituto de la Grasa (CSIC), Av. Padre Garcia Tejero, 4.41012 Seville, Spain \\ ${ }^{2}$ Royal Veterinary College, Royal College Street, London NW1 OTU, UK
}

(Received 24 February 2007 - Revised 18 May 2007 - Accepted 31 May 2007)

Minor components from dietary oils can modulate the atherogenic response of the TAG-rich lipoproteins (TRL) in which they are transported. In the present study we investigated the influence of TRL isolated from man after the intake of oleic acid-rich oils with different minor component compositions on VLDL secretion by rat primary hepatocytes. TRL were isolated from nine men after the intake of meals enriched with high-oleic sunflower oil (HOSO) or virgin olive oil (VOO) or VOO enriched with minor components (EVO). TRL were incubated with rat primary hepatocytes and the lipid accumulation was analysed in the cells and the secreted VLDL. The expression of genes for proteins related to hepatic lipid metabolism and VLDL production was also measured. Incubation of hepatocytes with TRL derived from HOSO as compared to VOO led to lower intracellular lipid accumulation and VLDL production despite higher mRNA expression for diacylglycerol-acyltransferase, microsomal TAG transfer protein, apoB and PPAR $\alpha$. When TRL derived from EVO were used there were no changes in VLDL secretion. These results suggest that incorporation of minor components from dietary high-oleic oils into TRL modulates the effect of these atherogenic particles on VLDL secretion.

Triacylglycerol-rich lipoprotein: VLDL: Liver: Virgin olive oil: PPAR $\alpha$

Dietary lipids are absorbed by enterocytes and secreted into lymph in the form of chylomicrons ${ }^{1}$. There is an increasing amount of data indicating that these TAG-rich lipoproteins (TRL) are atherogenic, since their remnant particles can cross the endothelial barrier and enter into the vascular wall ${ }^{2}$ where they can impair endothelial function ${ }^{3}$ and cause receptormediated lipid accumulation in macrophages, leading to foam cell formation ${ }^{4,5}$. The transformation of chylomicrons into remnant particles is dependent upon TAG hydrolysis by lipoprotein lipase, attached to the surface of the vascular endothelium ${ }^{6}$. The hepatic uptake of chylomicron remnants is mediated by apoE, which facilitates uptake via the LDL receptor and the LDL receptor-related protein by endocytosis ${ }^{7,8}$. It has become clear in recent years that dietary fatty acids affect hepatic gene expression for LDL receptor and LDL receptor-related protein $^{9,10}$. Within hepatocytes, VLDL are formed from the fusion of a droplet of previously stored TAG and newly synthesized apoB in two sequential stages ${ }^{11}$. In a first stage, a small quantity of TAG becomes associated with apoB during its co-translational translocation. This stage is accompanied by the acquisition of a phospholipid (PL) layer encapsulating the TAG. The formation of this precursor of the VLDL particle depends upon the microsomal TAG transfer protein (MTP) and the activity of enzymes responsible for lipid synthesis, such as acy-CoA-cholesterolacyltransferase and diacylglycerol-acyltransferase (DGAT). In the second stage of VLDL assembly, the bulk of the VLDL TAG is transferred to the primordial particle by its fusion with a larger droplet of TAG.

The Mediterranean diet, rich in virgin olive oil (VOO) has been proposed as a healthy dietary standard because it is associated with a low rate of cardiovascular mortality ${ }^{12}$. However, not all oleic acid-rich oils show the same effects. Indeed, VOO and high-oleic sunflower oil (HOSO) influence the magnitude and duration of the postprandial triacylglycerolaemia in normolipidaemic subjects in different ways ${ }^{13,14}$. Therefore, components other than the content of oleic acid, might be responsible for the postprandial responses to VOO, and possibly, for the effects of lipoproteins of dietary origin formed when the oil is consumed in the diet.

Since it is not possible to separate chylomicrons, chylomicron remnants and VLDL easily from blood, the TRL fraction is often used to study the metabolism and effects of lipoproteins of dietary origin. We have reported that the unsaponifiable fraction of VOO, contained in circulating TRL, improves the balance between vasoprotective and pro-thrombotic factors released by endothelial cells ${ }^{14}$ and that these minor components also affect the hepatic gene expression of LDL receptor-related protein in rats, hence affecting TRL internalization into the liver ${ }^{15}$.

Abbreviations: ACAT-2, acy-CoA-cholesterolacyltransferase-2; CE, cholesterol esters; DGAT, diacylglycerol-acyltransferase; EVO, enriched virgin olive oil; HOSO, high-oleic sunflower oil; MTP, microsomal TAG transfer protein; PL, phospholipid; TRL, TAG-rich lipoproteins; VOO, virgin olive oil.

* Corresponding author: Dr Valentina Ruiz-Gutierrez, fax +34 954616790, email valruiz@ig.csic.es 
Although we have demonstrated that the VLDL composition is differently influenced by the ingestion of HOSO or $\mathrm{VOO}^{16}$, it is not known whether the unsaponifiable fraction of these oils can affect the lipid metabolism and the secretion of VLDL in the liver. In the present study we aim to evaluate the influence of the unsaponifiable fraction of VOO on postprandial TRL composition and how this affects lipid metabolism and VLDL production in liver cells. With that purpose the composition of TRL collected from healthy volunteers after meals containing VOO, HOSO and VOO enriched in its unsaponifiable fraction (EVO) was compared, and the effects of the various types of TRL on the lipid content and VLDL secretion in cultured primary hepatocytes was assessed.

\section{Materials and methods}

\section{Diet study}

Nine male volunteers aged 26.5 (SD 3.6) years and BMI 24.9 (SD 1.4$) \mathrm{kg} / \mathrm{m}^{2}$ participated in the study. The volunteers had mean fasting plasma TAG concentration in the normal range $(1.1 \pm 0.2 \mathrm{mmol} / \mathrm{l})$ and did not suffer from any digestive or metabolic disease as verified by medical history. The subjects gave written, informed consent to a protocol approved by the Institutional Committee on Investigation in Humans (Hospital Universitario Virgen del Rocío, Sevilla) in accordance with the Helsinki declaration of 1975 as revised in 1983.

The test meal consisted of one slice of brown bread ( $28 \mathrm{~g})$; $100 \mathrm{~g}$ plain pasta (cooked with $200 \mathrm{ml}$ water); $130 \mathrm{~g}$ tomato sauce and one skimmed yoghurt, providing $2102 \mathrm{~kJ}$ of energy. HOSO, VOO or EVO $(70 \mathrm{~g})$ were supplied mixed with the tomato sauce (total energy $4523 \mathrm{~kJ}$ ). The enrichment of EVO was carried out by isolating the unsaponifiable fraction from VOO and adding it to another aliquot of VOO to a final concentration of $2.4 \%$. The fatty acid composition of VOO (v. hojiblanca; Hojiblanca, Antequera, Spain) and HOSO (purchased at the local market) used for the meals is shown in Table 1. The unsaponifiable fraction of the oils was also analysed and is presented in Table 2.

Table 1. Fatty acid composition ( $\mathrm{mg} / 100 \mathrm{mg}$ ) of high-oleic sunflower oil (HOSO) and virgin olive oil (VOO)

\begin{tabular}{lccccc}
\hline & \multicolumn{2}{c}{ HOSO } & & \multicolumn{2}{c}{ VOO } \\
\cline { 2 - 3 } \cline { 5 - 6 } & Mean & SEM & & Mean & SEM \\
\hline $16: 0$ & $4 \cdot 2$ & 0.1 & & $13 \cdot 5^{*}$ & 0.4 \\
$16: 1 n-7$ & 0.1 & 0.0 & & 0.5 & 0.3 \\
$17: 0$ & 0.1 & 0.0 & & 0.3 & 0.1 \\
$18: 0$ & 4.4 & 0.2 & & $2.3^{*}$ & 0.3 \\
$18: 1 n-9$ & 79.3 & 0.6 & & 76.5 & 0.6 \\
$18: 1 n-7$ & ND & & & 0.1 & 0.0 \\
$18: 2 n-6$ & 10.4 & 0.7 & & $5 \cdot 6^{*}$ & 0.7 \\
$18: 3 n-3$ & 0.1 & 0.0 & & 0.7 & 0.1 \\
$18: 3 n-6$ & 0.4 & 0.0 & & 0.4 & 0.0 \\
$20: 1 n-9$ & 0.2 & 0.0 & & 0.3 & 0.1 \\
$22: 0$ & 0.7 & 0.2 & & $0.2^{*}$ & 0.1 \\
\hline
\end{tabular}

$\mathrm{ND}$, not detected

Mean values were significantly different from those of the HOSO group: ${ }^{\star} P<0.05$
Table 2. Unsaponifiable fraction composition ( $\mathrm{mg} / \mathrm{kg}$ ) of high-oleic sunflower oil (HOSO) and virgin olive oil (VOO)

\begin{tabular}{lccccc}
\hline & \multicolumn{2}{c}{ HOSO } & & \multicolumn{2}{c}{ VOO } \\
\cline { 2 - 3 } \cline { 5 - 6 } & Mean & SEM & & Mean & SEM \\
\hline Squalene & ND & & & 6621 & 235 \\
Total sterols & 1497 & 54 & 1558 & 33 \\
Total tocopherols & 393 & 25 & $207^{\star}$ & 48 \\
Erythrodiol + uvaol & ND & & & 20.98 & 1.07 \\
Waxes & 30.0 & 4.8 & & $83.5^{\star}$ & 7.9 \\
\hline
\end{tabular}

ND, not detected.

Mean values were significantly different from those of the HOSO group: ${ }^{*} P<0.05$.

Participants were asked to refrain from smoking and drinking during the preceding day of the study, given their influence on lipid metabolism. During the course of the study the participants were allowed to drink water and/or black coffee without sugar and undertook only light activities. A baseline fasting blood sample was collected into vacutainer tubes immediately before the subjects ate the test meal. Blood samples were drawn $2 \mathrm{~h}$ after the intake of the test meals. The study was designed as a short-term double-blinded study and was carried out over two 1-week periods with a 1 -week washout period between them.

\section{Lipoprotein determination}

Serum was recovered rapidly by centrifugation (1700 $\mathrm{g}$, $\left.20 \mathrm{~min}, 12^{\circ} \mathrm{C}\right)$. NaAzide ( $\left.1 \mathrm{~mol} / \mathrm{l}\right)$, phenylmethylsulphonyl fluoride $(10 \mathrm{mmol} / \mathrm{l}$ in isopropanol) and aprotinin $(1400 \mu \mathrm{g} / \mathrm{ml})$ were added to the plasma to a final concentration of $1 \mathrm{mmol} / 1,10 \mu \mathrm{mol} / 1$ and $28 \mu \mathrm{g} / \mathrm{ml}$, respectively. TRL were isolated from $4 \mathrm{ml}$ of serum layered with $6 \mathrm{ml}$ of a $\mathrm{NaCl}$ solution (density $1.006 \mathrm{~g} / \mathrm{ml}$ ) by a single ultracentrifugation spin $\left(356000 \mathrm{~g}, 18 \mathrm{~h}, 15^{\circ} \mathrm{C}\right)$. Ultracentrifugation was performed using a SW $41 \mathrm{Ti}$ rotor in a Beckman L8-70M preparative ultracentrifuge (Beckman Instruments, Palo Alto, CA, USA).

\section{TAG-rich lipoprotein lipid composition}

Total lipids were extracted from TRL following a modification of the method of Folch et al. ${ }^{17}$, using butylated hydroxytoluene as antioxidant. The lipids extracted were redissolved in $1 \mathrm{ml}$ chloroform-methanol $(2: 1, \mathrm{v} / \mathrm{v})$ and preserved at $-20^{\circ} \mathrm{C}$ until used. The lipid classes composition was determined by HPLC as described by Perona \& Ruiz-Gutierrez ${ }^{18}$. In brief, $10 \mu \mathrm{l}$ of lipids were dissolved in chloroform-methanol $(2: 1, \mathrm{v} / \mathrm{v})$ and injected by an automatic sampler into a 2690 Alliance liquid chromatograph (Waters, Milford, MA, USA) controlled by the Millennium 34 System (Waters). Detection was accomplished with a light-scattering detector (DDL31 Eurosep; Ins, Cergy-Pontoise, France). The separation of lipid classes was carried out on a Lichrosphere diol column $(250 \times 4.6 \mathrm{~mm}, 5 \mu \mathrm{m}$ particle size; Merck, Darmstadt, Germany) using a gradient elution system containing hexane, 2-propanol and methanol. Stock solutions of cholesteryl oleate, triolein, cholesterol and phosphatidylcholine were prepared in chloroform-methanol $(2: 1, \mathrm{v} / \mathrm{v})$ and used as standard for identification and quantification of cholesteryl esters (CE), TAG, free cholesterol and PL, respectively. 
TAG and PL were isolated by solid-phase extraction diol columns (Supelclean ${ }^{\mathrm{TM}}$ LC-Diol; Supelco, Bellefonte, PA, USA) using hexane-methylene chloride $(9: 1, \mathrm{v} / \mathrm{v})$ as eluent. The eluate was evaporated to dryness under a stream of nitrogen and redissolved in hexane. TAG and PL were transmethylated using sodium methoxide in methanol $(0.5 \%)$ and the resulting fatty acid methyl esters were analysed by GC, using a model 5890 series II gas chromatograph (Hewlett-Packard, Avondale, USA) equipped with a flame ionization detector and a capillary silica column Supelcowax 10 (Sulpelco) of $60 \mathrm{~m}$ length and $0.25 \mathrm{~mm}$ internal diameter as previously described ${ }^{19}$.

TAG were analysed for their molecular species as described previously ${ }^{20}$. The chromatographic system consisted of a model 2690 Alliance liquid chromatograph (Waters), provided with a Spherisorb S3 ODS2 $(250 \times 4.6 \mathrm{~mm})$ of $3 \mu \mathrm{m}$ particle size (Waters). The liquid chromatograph was coupled to a light-scattering detector model 2420 (Waters). The system was controlled by computer through the Millennium 34 System (Waters). The mobile phase consisted on an initial elution gradient of $20 \%$ of acetone in acetonitrile raising the percentage of acetone to $45 \%$ in $12 \mathrm{~min}$ and then to $80 \%$ after $60 \mathrm{~min}$. This percentage was held up to the end of the analysis. The flow rate was $1 \mathrm{ml} / \mathrm{min}$. Tripled runs of six concentrations of these standards (Sigma-Aldrich, Co., St. Louis, MO, USA) (between 0.25 and $2.5 \mathrm{mg} / \mathrm{ml}$ in hexane) were injected: tritridecanoin, 1,3-dioleoyl-2-palmitoyl-glycerol, trimyristin, 1,3-dioleoyl-2-stearoyl-glycerol, 1,3-dioleoyl-2linoleoyl-glycerol, tripentadecanoin, tripalmitin, triolein and trilinolein. Various regression models were tested and finally fourth regression curves $\left(r^{2} \geq 0.999\right)$ were chosen. Equations resulting from these curves were employed for quantification.

\section{Preparation and culture of hepatocytes}

Male Wistar rats (300-350 g body mass) were kept on a standard low-fat pellet diet, housed at constant day length $(12 \mathrm{~h})$ and temperature $\left(25^{\circ} \mathrm{C}\right)$ and allowed access ad libitum to food and water. Hepatocytes were prepared from rat livers by perfusion with collagenase (Sigma-Aldrich Chemical Co., Poole, UK) as described before ${ }^{21}$ and re-suspended in RPMI 1640 medium (Invitrogen, Paisley, UK) supplemented with $\mathrm{NaHCO}_{3}(2 \mathrm{~g} / \mathrm{l})$, pyruvate $(110 \mathrm{mg} / \mathrm{l})$, dexamethasone $(1 \mu \mathrm{M})$, penicillin/streptomycin $(100 \mathrm{mg} / \mathrm{ml})$ and gentamycin $(50 \mathrm{mg} / \mathrm{l})$ (culture medium) (Sigma-Aldrich Chemical Co.). Viable cells were then separated from non-viable cells using a Percoll (Sigma-Aldrich Chemical Co.) gradient $(0-70 \%)^{22}$. The viable cells were washed twice with culture medium, re-suspended in culture medium containing $10 \%(\mathrm{v} / \mathrm{v})$ fetal bovine serum (heat inactivated at $56^{\circ} \mathrm{C}$ for $30 \mathrm{~min}$ before use) and insulin $(4 \mathrm{mg} / \mathrm{ml}$; Sigma-Aldrich Chemical Co.) and cultured in Primaria-coated plastic dishes at $37^{\circ} \mathrm{C}$ in an atmosphere of $95 \%$ air : $5 \% \mathrm{CO}_{2}$ as described by Isusi et al. ${ }^{22}$. Cell viability as assessed by Trypan blue exclusion was $>90 \%$ in all experiments. After $2-3 \mathrm{~h}$ in culture the cells adhered to the dishes, the medium and any non-adherent cells were removed and culture medium containing $60 \mu \mathrm{g} / \mathrm{ml}$ insulin was added.

\section{mRNA expression}

To determine the effects of the different types of TRL on mRNA expression for apoB, acyl-CoA-cholesterolacyltransferase-2
(ACAT-2), MTP, DGAT and PPAR $\alpha$, the particles (final concentration $160 \mu \mathrm{g}$ TAG/ml) were incubated with hepatocytes for $5 \mathrm{~h}$, the medium was then removed, the cells were washed with PBS $(3 \times 1 \mathrm{ml})$ and the total RNA was extracted as described later. mRNA expression for apoB, ACAT-2, MTP, DGAT and PPAR $\alpha$ were determined by RT-PCR. Total RNA was extracted from hepatocytes using a kit (Promega UK, Southampton, UK) according to the manufacturer's instructions. First strand DNA synthesis was performed using avian myeloblastosis virus RT and amplification was carried out using the following primers for the appropriate rat $(\mathrm{apoB}, \operatorname{PPAR} \alpha)$ or mouse (ACAT-2, DGAT and MTP) genes: ACAT-2, sense, 5' CCATTGATCTATTCCCTTGTCC-3', antisense, 5'-GAGTCCTTGGGTAGTTGTCTCG-3'; DGAT, sense, 5'-GTGGTGATGCTGATCCTGAGT-3', antisense, GAGTATGATGCCAGAGCAAAC-3', apoB, sense, 5'-TACCTCCGGCAGCTCCATTCC- $3^{\prime}$, antisense, $5^{\prime}$-TGCGCTTCCTGCTCTTGCTGTT-3'; PPAR $\alpha$, sense $5^{\prime}$-TGACGACAAGTGTGATCGAAGC- $3^{\prime}$, antisense, 5'-GTTGCTAGTCTTTCCTGCGAGT-3'; MTP, sense 5'-GCTGGAAGGCTTAATTGCAG-3', antisense, 5' - CGGGTTTTAGACTCGCGATA-3'. Initial denaturation was carried out at $95^{\circ} \mathrm{C}$ for $15 \mathrm{~min}$, followed by $30(\mathrm{apoB}, \mathrm{PPAR} \alpha), 32$ (DGAT and MTP) or 35 (ACAT-2) cycles consisting of denaturation at $94^{\circ} \mathrm{C}$ for $1 \mathrm{~min}$, annealing at $56^{\circ} \mathrm{C}$ (apoB and ACAT-2), $58^{\circ} \mathrm{C}$ (DGAT and MTP) or $60^{\circ} \mathrm{C}(\mathrm{PPAR} \alpha)$ for $1 \mathrm{~min}$, extension at $72^{\circ} \mathrm{C}$ for $1 \mathrm{~min}$, followed by final extension at $72^{\circ} \mathrm{C}$ for $10 \mathrm{~min}$. The products (ACAT-2, $300 \mathrm{bp}$; DGAT, $329 \mathrm{bp}$; apoB, $340 \mathrm{bp}$, PPAR $\alpha, 301 \mathrm{bp}$ and MTP $321 \mathrm{bp}$ ) were analysed by electrophoresis using agarose gels $(1.2 \%, \mathrm{w} / \mathrm{v})$ containing ethidium bromide $(0.5 \mu \mathrm{g} / \mathrm{ml})$. Product size was verified using a $100 \mathrm{bp}$ DNA ladder standard (Promega UK). The bands were quantified by optical density volume analysis and were normalized using the values obtained simultaneously for glyceraldehyde-3-phosphate dehydrogenase in the samples in the same assay system. The linearity of the assay for each gene was established in preliminary experiments.

\section{Hepatocyte lipid accumulation and VLDL production}

For experiments on lipid accumulation in hepatocytes and VLDL lipid composition, hepatocytes were incubated with or without (control) TRL (final concentration $240 \mu \mathrm{g}$ TAG/ $\mathrm{ml}$ ) for $5 \mathrm{~h}$, the medium was then removed and replaced with fresh medium without TRL. After $18 \mathrm{~h}$ the medium was collected and the cells were washed with PBS $(3 \times 1 \mathrm{ml})$. The medium was centrifuged at $40000 \mathrm{rpm}$ for $16 \mathrm{~h}$ at $\rho=1.050 \mathrm{~g} / \mathrm{ml}$ and the top fraction containing VLDL was obtained by tube slicing. The cells were harvested from the dishes and washed twice with PBS. Lipids from VLDL and cells were extracted with chloroform-methanol $(2: 1$, v/v) and analysed using kits supplied by Sigma-Aldrich Co. To take account of the small variation in the number of cells in each dish from experiment to experiment, the results are expressed as ng lipid/mg cell protein.

\section{Data analysis}

Results are expressed as means and their standard errors, unless otherwise stated. A Prism 4.0 statistical package (GraphPad Software Inc., San Digo, CA, USA) was used for all the analyses. Multiple groups were compared by one-way 
ANOVA with repeated measures, followed by Tukey's test to assess specific group differences. Differences were considered significant at $P<0 \cdot 05$.

\section{Results}

Fatty acid and unsaponifiable fraction composition of virgin olive oil and high-oleic sunflower oil

Both oils had a similar amount of MUFA $(79.6 \%$ for HOSO and $77.4 \%$ for VOO) with oleic acid (18:1n-9) accounting for $99 \%$ of all MUFA (Table 1). Although VOO had a higher content of SFA, due to a higher percentage of palmitic $(16: 0)$ and docosanoic $(22: 0)$ acids $(P=0.05)$, the content of stearic acid $(18: 0)$ was higher in HOSO $(P=0 \cdot 05)$. In contrast, HOSO had a higher amount of linoleic acid $(18: 2 n-6$; $P=0.05$ ). The fatty acid composition of EVO was the same as VOO, as this was not modified when supplemented with the unsaponifiable fraction.

Squalene and erythrodiol were absent from the unsaponifiable fraction of HOSO, but were present in high concentrations in VOO (Table 2). Also, the wax concentration was higher in VOO. The sterol concentration did not differ between the oils. In contrast, the tocopherol concentration was higher in HOSO $(P=0.02)$. The unsaponifiable fraction composition of EVO was the same as VOO but the concentration was doubled.

Effect of virgin olive oil, enriched virgin olive oil and higholeic sunflower oil on the lipid composition of TAG-rich lipoproteins

TRL contained higher TAG concentrations $2 \mathrm{~h}$ after consumption of the HOSO-enriched meal compared with EVO TRL and VOO TRL (Fig. 1). In contrast, EVO TRL was richer in the rest of the lipid classes analysed, thus showing higher concentrations of PL, free cholesterol and CE. Unlike EVO TRL, the PL, free cholesterol and CE concentrations in particles

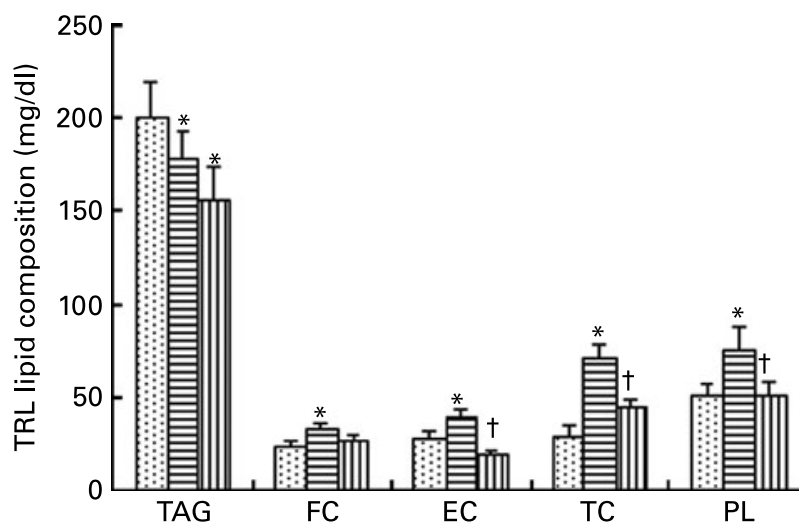

Fig. 1. Lipid classes composition of TAG-rich lipoproteins (TRL) obtained $2 \mathrm{~h}$ after the intake of virgin olive oil (VOO, 四), enriched virgin olive oil (EVO, 望) and high-oleic sunflower oil (HOSO, 贯). CE, cholesterol esters; FC, free cholesterol; PL, phospholipids; TC, total cholesterol. Values are means with their standard errors depicted by vertical bars $(n 9)$. Mean values were significantly different from those of the HOSO group: ${ }^{\star} P<0.05$. Mean values were significantly different from those of the EVO group: $\dagger P<0.05$. derived from the intake of VOO were similar to those in HOSO TRL.

The most abundant TAG molecular species found in the TRL after feeding VOO and EVO were triolein and dioleoyl-palmitoyl-glycerol, accounting for around $50 \%$ of total TAG species (Table 3) and there was no difference in the TAG composition of TRL after consumption of these dietary oils, except for a slight difference in linoleoyl-dipalmitoylglycerol. HOSO-derived TRL, however, showed more differences in TAG molecular species as compared to VOO and EVO. These particles were rich in linoleic acid-containing TAG (dilinoleoyl-oleoyl-glycerol, linoleoyl-dioleoyl-glycerol, linoleoyl-oleoyl-palmitoyl-glycerol and linoleoyl-dipalmitoylglycerol) and depleted in triolein and palmitic acid-containing TAG (dioleoyl-palmitoyl-glycerol).

Although important differences were found in oleic and palmitic acid-containing TAG, no differences were found in the proportion of these fatty acids in TAG. The linoleic acid concentration was higher and arachidonic acid $(20: 4 n-6)$ lower in HOSO TRL. The content of palmitoleic $(16: 1 n-7)$ and stearic acids was higher in EVO TRL compared with HOSO TRL and VOO TRL (Table 4).

Despite the oleic acid concentration being similar in VOO and HOSO, in TRL PL derived from HOSO the concentration of oleic acid was lower (Table 5). In contrast, HOSO particles presented high concentrations of palmitic and linoleic acids. This resulted in higher SFA and $n-6$ PUFA in TRL PL after the intake of HOSO. Interestingly, the $n-3$ PUFA content was higher in TRL PL after consumption of VOO and EVO. It is also interesting to note that some fatty acids differed in PL of EVO TRL and VOO TRL. Whereas the concentration of palmitoleic acid was higher in EVO TRL, that of arachidonic acid and its precursor dihomo- $\gamma$-linolenic $(20: 3 n-6)$ acid were lower.

Table 3. TAG molecular species composition ( $\mathrm{mg} / 100 \mathrm{mg}$ ) of TAG-rich lipoproteins collected $2 \mathrm{~h}$ after the intake of virgin olive oil (VOO), enriched virgin olive oil (EVO) or high-oleic sunflower oil (HOSO)

\begin{tabular}{|c|c|c|c|c|c|c|}
\hline & \multicolumn{2}{|c|}{ HOSO } & \multicolumn{2}{|c|}{ EVO } & \multicolumn{2}{|c|}{ VOO } \\
\hline & Mean & SEM & Mean & SEM & Mean & SEM \\
\hline LLO & $2 \cdot 25$ & 0.32 & $1.09^{*}$ & 0.22 & $0.96^{*}$ & 0.11 \\
\hline LLP & $4 \cdot 86$ & 0.42 & 5.08 & 1.06 & $7 \cdot 34$ & 0.94 \\
\hline LnOo & 1.94 & 0.50 & $1 \cdot 18$ & 0.38 & 0.74 & 0.12 \\
\hline LOO & $9 \cdot 28$ & $1 \cdot 31$ & $3 \cdot 99^{\star * *}$ & 0.46 & $4 \cdot 15^{\star \star \star}$ & 0.54 \\
\hline LOP & $17 \cdot 35$ & 1.23 & $11 \cdot 52^{\star \star}$ & 1.14 & $12 \cdot 37^{\star}$ & $1 \cdot 31$ \\
\hline LPP & 24.84 & 0.92 & $17 \cdot 60^{\star \star *}$ & 0.51 & $14 \cdot 70^{* * *} \dagger$ & 0.95 \\
\hline 000 & 12.01 & 0.74 & $23 \cdot 83^{\star \star \star}$ & 1.88 & $25 \cdot 83^{\star \star \star}$ & 2.67 \\
\hline OOP & $17 \cdot 81$ & $1 \cdot 12$ & $26 \cdot 75^{\star \star}$ & $2 \cdot 23$ & $26 \cdot 51^{\star *}$ & $1 \cdot 30$ \\
\hline OPP & 1.72 & 0.23 & 1.67 & 0.21 & 1.57 & 0.12 \\
\hline PPP & 3.62 & 0.29 & 3.28 & 0.32 & $2 \cdot 55^{\star}$ & 0.18 \\
\hline OOS & 1.58 & 0.29 & $1 \cdot 10$ & 0.15 & 0.97 & 0.19 \\
\hline OPS & 0.68 & 0.04 & $1 \cdot 01^{*}$ & 0.10 & $1.06^{\star *}$ & 0.08 \\
\hline Others & 2.07 & 0.21 & $1 \cdot 89$ & 0.22 & $1 \cdot 26^{\star}$ & 0.16 \\
\hline
\end{tabular}

LLO, dilinoleoyl-oleoyl-glycerol; LLP, dilinoleoyl-pamitoleoyl-glycerol; LnOO, linolenoyl-dioleoyl-glycerol; LOO, linoleoyl-dioleoyl-glycerol; LOP, linoleoyl-oleoyl-palmitoyl-glycerol; LPP, linoleoyl-dipalmitoyl-glycerol; OOO, trioleoyl-glycerol; OOP, dioleoyl-palmitoyl-glycerol; OPP, oleoyl-dipalmitoyl-glycerol; PPP, tripalmitoyl-glycerol; OOS, dioleoyl-stearoyl-glycerol; OPS, dioleoyl-palmitoyl-glycerol.

Mean values were significantly different from those of the HOSO group: ${ }^{\star} P<0.05$; ${ }^{\star \star} P<0.01 ;{ }^{\star \star \star} P<0.001$.

Mean values were significantly different from those of the EVO group: $\dagger P<0.05$. 
Table 4. TAG fatty acid composition ( $\mathrm{mg} / 100 \mathrm{mg}$ ) of TAG-rich lipoproteins collected $2 \mathrm{~h}$ after the intake of virgin olive oil (VOO), enriched virgin olive oil (EVO) or high-oleic sunflower oil (HOSO)

\begin{tabular}{|c|c|c|c|c|c|c|}
\hline & \multicolumn{2}{|c|}{ HOSO } & \multicolumn{2}{|c|}{ EVO } & \multicolumn{2}{|c|}{ VOO } \\
\hline & Mean & SEM & Mean & SEM & Mean & SEM \\
\hline $14: 0$ & 0.59 & 0.06 & ND & & 0.37 & 0.02 \\
\hline $16: 0$ & $21 \cdot 32$ & 0.87 & 23.56 & 0.72 & 21.76 & 1.63 \\
\hline $16: 1 n-9$ & 1.86 & 0.40 & 2.04 & 0.26 & 1.18 & 0.14 \\
\hline $16: 1 n-7$ & 1.22 & 0.24 & $1.82^{\star *}$ & 0.32 & 1.45 & 0.31 \\
\hline $18: 0$ & 2.89 & 0.48 & $6 \cdot 06^{\star *}$ & 0.72 & $3.30 \dagger$ & 0.61 \\
\hline $18: 1 n-9$ & 47.88 & 1.42 & 48.09 & 1.92 & 52.40 & 1.84 \\
\hline $18: 1 n-7$ & 2.45 & 0.26 & $2 \cdot 22$ & 0.08 & 2.51 & 0.30 \\
\hline $18: 2 n-6$ & 13.79 & 1.81 & $9.05^{*}$ & $1 \cdot 10$ & $9 \cdot 18^{*}$ & 1.47 \\
\hline $18: 3 n-3$ & $5 \cdot 26$ & 1.54 & 4.17 & 0.46 & 4.51 & 0.57 \\
\hline $20: 3 n-6$ & 0.84 & 0.09 & 0.65 & 0.02 & 0.84 & 0.05 \\
\hline $20: 4 n-6$ & 0.87 & 0.17 & 1.39 & 0.22 & $1 \cdot 73^{\star \star}$ & 0.23 \\
\hline $20: 5 n-3$ & 1.03 & 0.12 & 0.96 & 0.03 & 0.78 & 0.08 \\
\hline SFA & 24.80 & 1.39 & $29 \cdot 62$ & 1.48 & 25.43 & 2.04 \\
\hline MUFA & 53.41 & 2.42 & $54 \cdot 17$ & 1.68 & 57.54 & 2.32 \\
\hline PUFA $n-6$ & 15.50 & 1.84 & 11.09 & $1 \cdot 14$ & 11.75 & 1.51 \\
\hline PUFA $n-3$ & 6.29 & 1.26 & $5 \cdot 13$ & 0.79 & $5 \cdot 29$ & 0.69 \\
\hline
\end{tabular}

ND, not detected.

Mean values were significantly different from those of the HOSO group: ${ }^{*} P<0.05$; ${ }^{* *} P<0.01$.

Mean values were significantly different from those of the EVO group: $\dagger P<0.05$.

Table 5. Phospholipid fatty acid composition ( $\mathrm{mg} / 100 \mathrm{mg}$ ) of TAG-rich lipoproteins collected $2 \mathrm{~h}$ after the intake of virgin olive oil (VOO), enriched virgin olive oil (EVO) or high-oleic sunflower oil (HOSO)

\begin{tabular}{|c|c|c|c|c|c|c|}
\hline & \multicolumn{2}{|c|}{ HOSO } & \multicolumn{2}{|c|}{ EVO } & \multicolumn{2}{|c|}{ VOO } \\
\hline & Mean & SEM & Mean & SEM & Mean & SEM \\
\hline $14: 0$ & $1 \cdot 77$ & 0.46 & 1.76 & 0.28 & $1 \cdot 25$ & 0.14 \\
\hline $14: 1 n-5$ & 0.97 & 0.18 & 0.78 & 0.48 & 0.83 & 0.03 \\
\hline $16: 0$ & 30.74 & 1.39 & $22 \cdot 85^{\star}$ & 1.22 & $24 \cdot 21^{\star \star}$ & 2.03 \\
\hline $16: 1 n-9$ & 1.45 & 0.47 & 0.93 & 0.06 & 1.14 & 0.15 \\
\hline $16: 1 n-7$ & 0.93 & 0.09 & $2 \cdot 25^{\star \star \star}$ & $0 \cdot 21$ & 0.86††† & $0 \cdot 14$ \\
\hline $18: 0$ & $15 \cdot 82$ & 1.63 & $12 \cdot 19$ & $2 \cdot 17$ & $13 \cdot 50$ & 0.77 \\
\hline $18: 1 n-9$ & $13 \cdot 11$ & 0.65 & $27 \cdot 70^{\star \star}$ & 4.46 & $24.54^{\star}$ & 2.94 \\
\hline $18: 1 n-7$ & 1.54 & 0.09 & $2 \cdot 90^{\star \star \star}$ & 0.26 & $2 \cdot 90^{\star \star \star}$ & 0.05 \\
\hline $18: 2 n-6$ & 22.85 & $1 \cdot 36$ & $18 \cdot 36^{\star}$ & 1.05 & $18 \cdot 23^{*}$ & 1.66 \\
\hline $18: 3 n-3$ & ND & & 3.68 & 0.33 & 2.47 & 0.54 \\
\hline $20: 3 n-6$ & 0.56 & 0.18 & 0.63 & 0.02 & $1.96^{* \star *} \dagger$ & 0.28 \\
\hline $20: 4 n-6$ & 9.82 & 1.05 & $5 \cdot 14^{\star \star}$ & 0.83 & $7.35 \dagger$ & 0.85 \\
\hline $20: 5 n-3$ & 0.42 & 0.09 & $0 \cdot 80^{*}$ & 0.01 & $0.79^{\star}$ & 0.12 \\
\hline SFA & 48.33 & $2 \cdot 48$ & $36 \cdot 8^{\star \star}$ & 1.67 & $38 \cdot 96^{\star \star}$ & 1.94 \\
\hline MUFA & 18.00 & 1.49 & $34.56^{\star \star \star}$ & 3.47 & $30 \cdot 27^{\star \star}$ & $1 \cdot 31$ \\
\hline PUFA $n-6$ & 33.23 & 2.58 & $24 \cdot 13^{\star}$ & 1.90 & 27.54 & $2 \cdot 78$ \\
\hline PUFA $n-3$ & 0.42 & 0.09 & $4.48^{\star \star \star}$ & 0.34 & $3 \cdot 26^{\star \star \star}$ & 0.66 \\
\hline
\end{tabular}

ND, not detected.

Mean values were significantly different from those of the HOSO group: ${ }^{*} P<0.05$ ${ }^{* \star} P<0.01 ;{ }^{* *} P<0.001$.

Mean values were significantly different from those of the EVO group: $\dagger P<0.05$ $\dagger \dagger+P<0.001$.

Effect of TAG-rich lipoprotein derived from virgin olive oil, enriched virgin olive oil and high-oleic sunflower oil on lipid accumulation and VLDL secretion by rat primary hepatocytes

TRL derived from VOO, EVO or HOSO were incubated with cultured rat hepatocytes for $5 \mathrm{~h}$ to measure the lipid accumulation after the uptake. The results are shown in
Fig. 2(a). Lipid accumulation after incubation with HOSO TRL did not differ from that found in control cells incubated with the same volume $(300 \mu \mathrm{l})$ of PBS instead of TRL. In contrast, incubation with EVO TRL and VOO TRL resulted in increased accumulation of TAG in hepatocytes, although no modification of the cellular content of total, free or esterified cholesterol was observed.

For determination of VLDL secretion, the medium containing TRL was removed, fresh TRL-free medium was added and cells were incubated for a further $18 \mathrm{~h}$ before the VLDL was isolated from the medium and the lipid content determined. Figure 2(b) shows the results. All the TRL increased the TAG and total cholesterol content of the secreted VLDL. The free cholesterol content was also significantly raised by all three TRL types, while the $\mathrm{CE}$ concentrations were increased by EVO and VOO, but not HOSO TRL. However, the highest lipid concentrations of both TAG and cholesterol in VLDL were observed after incubation with VOO TRL. Although both TAG and cholesterol concentrations were slightly higher in VLDL after
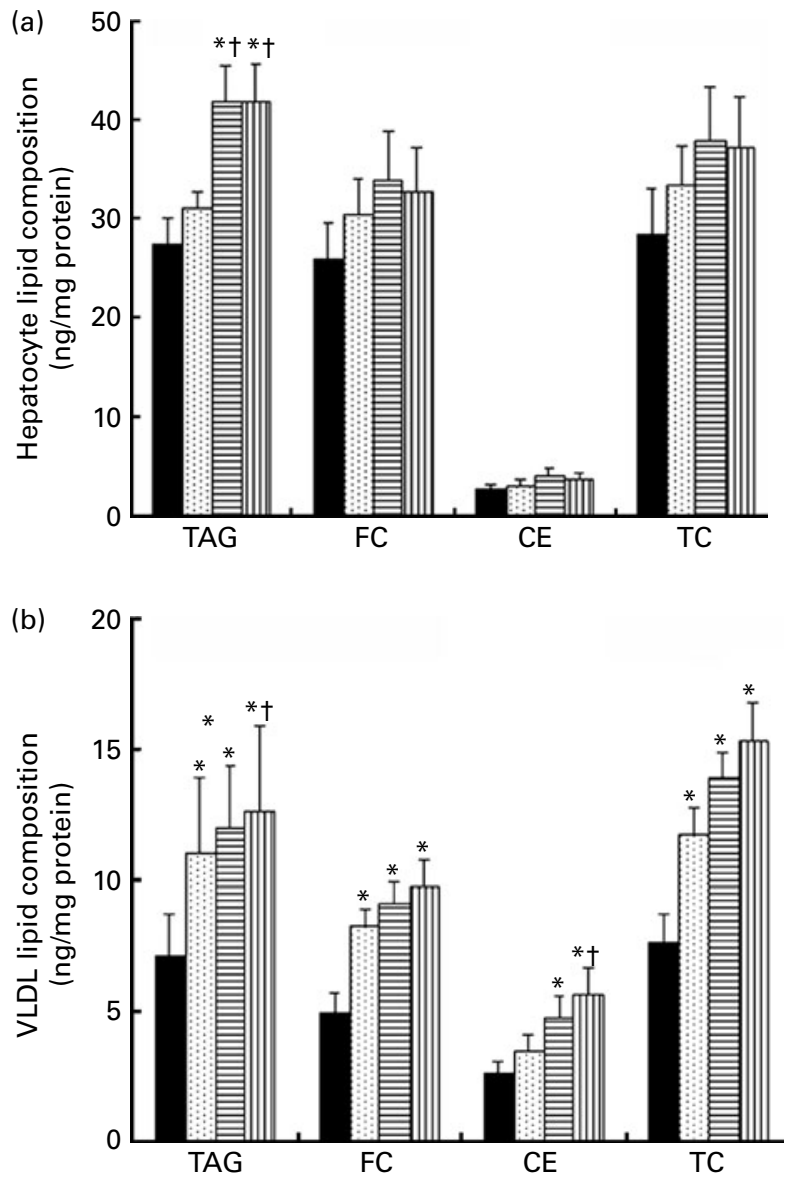

Fig. 2. Lipid classes composition ( $\mathrm{ng} / \mathrm{mg}$ cell protein) of rat primary hepatocytes (a) and secreted VLDL (b) after incubation with or without (control, TAG-rich lipoproteins obtained $2 \mathrm{~h}$ after the intake of virgin olive oil (VOO, $\mathbb{1}$ ), enriched virgin olive oil (EVO, 司) and high-oleic sunflower oil (HOSO, 垌). CE, cholesterol esters; FC, free cholesterol; TC, total cholesterol. Values are means with their standard errors depicted by vertical bars $(n 9)$. Mean values were significantly different from those of the control group: ${ }^{\star} P<0.05$. Mean values were significantly different from those of the HOSO group: $\dagger P<0.05$. 
incubation with VOO TRL, the differences were not significant compared with those particles after incubation with EVO TRL.

Effect of TAG-rich lipoprotein derived from virgin olive oil, enriched virgin olive oil and high-oleic sunflower oil on mRNA expression for proteins related to lipid synthesis and $V L D L$ production

The expression of mRNA for ACAT-2 was not modified in hepatocytes by incubation with any of the TRL tested (Fig. 3). In contrast, mRNA concentrations for apoB and MTP were increased after HOSO TRL and EVO TRL but not after VOO TRL. Additionally, the relative abundance of mRNA transcripts for DGAT and PPAR $\alpha$ was down-regulated by VOO TRL. The latter gene was also down-regulated after incubation with EVO TRL.

\section{Discussion}

As expected from previous studies ${ }^{14,15}$ we observed differences in the TRL composition after the intake of meals enriched with HOSO, VOO and EVO. The intake of HOSO increased the TAG content in postprandial TRL as compared to VOO and EVO by increasing the content of linoleic acid in TAG in the form of linoleoyl-dioleoyl-glycerol, dilinoleoyl-oleoyl-glycerol, linoleoyl-oleoyl-palmitoyl-glycerol and dilinoleoyl-palmitoyl-glycerol. This effect had been reported before in $\operatorname{man}^{13}$ and we have suggested that modifications in TAG molecular species contributed to the differential effects of HOSO and VOO on the production of eicosanoids by endothelial cells ${ }^{14}$. The transformation of chylomicrons and VLDL into remnant particles is dependent upon TAG hydrolysis by lipoprotein lipase, which exhibits specificity with respect to fatty acid length chain and unsaturation ${ }^{6}$. Therefore, the composition of TRL TAG, which in turn depends on the TAG composition of the dietary oils, is decisive for the activity of lipoprotein lipase and remnant formation. The PL concentration in HOSO and VOO TRL was similar, while that of EVO TRL was increased in comparison. However, the fatty acid composition of this lipid class was similar in EVO and

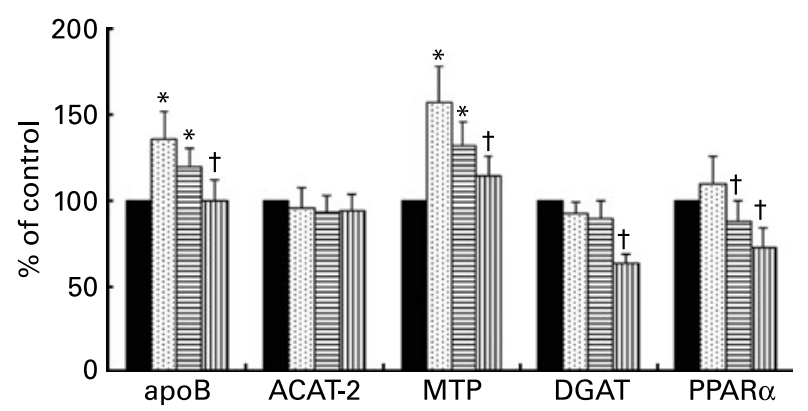

Fig. 3. mRNA expression for apoB, acyl-cholesterolacyltransferase-2 (ACAT2), microsomal TAG transfer protein (MTP), diacylglycerol-acyltransferase (DGAT) and PPAR $\alpha$ of rat primary hepatocytes after incubation with or without (control, $\square$ ) TAG-rich lipoproteins (TRL) obtained $2 \mathrm{~h}$ after the intake of virgin olive oil (VOO, 四), enriched virgin olive oil (EVO, 亘) and high-oleic sunflower oil (HOSO, 典). Values (expressed as the percentage of the values obtained after the incubation of the cells in medium without TRL) are means with their standard errors depicted by vertical bars $(n 9)$. Mean values were significantly different from those of the control group: ${ }^{\star} P<0.05$. Mean values were significantly different from those of the HOSO group: $\dagger P<0.05$.
VOO TRL, with HOSO TRL showing more differences. Specifically, the linoleic acid content was increased, as found for TAG, along with palmitic acid, while the concentration of oleic acid was lower after HOSO consumption. Therefore, our present data confirm that, in spite of their similar very high oleic acid concentration, HOSO and VOO have differential effects on TRL lipid composition, which in turn may directly influence their clearance from plasma.

Increasing the unsaponifiable content in VOO also modified the TRL lipid composition. Despite free cholesterol, total TAG, TAG molecular species and TAG fatty acids being unaffected postprandially by EVO as compared to VOO consumption, total cholesterol and CE as well as PL concentrations were raised. In addition, the PL fatty acid composition was differentially modified after the intake of VOO or EVO, indicating that supplementation of VOO with its own minor components affect the incorporation of PL into the TRL particle. Although postprandial TRL consist of both intestinal chylomicrons and hepatic VLDL, we assume that the variations observed in PL fatty acid composition are due to the effect of the dietary oils on chylomicrons, as at $2 \mathrm{~h}$ after the intake of the oils, the effect on VLDL composition should be negligible. Chylomicron assembly is similar to that of VLDL; hence they are formed by a droplet of TAG with some CE, stabilized by a shell of PL, cholesterol and protein. Whereas TAG used for assembly are newly (re-)synthesized, these particles contain more preformed than nascent PL. In the process of chylomicron assembly, PL are incorporated during the translocation of apoB to the endoplasmic reticulum to form the 'primordial particle'. In a second stage, the primordial particle is further lipidated by the action of $\mathrm{MTP}^{23}$. The incorporation of PL into the nascent lipoprotein is critical and it is believed that one of their functions is to stabilize apoB during its translocation into the endoplasmic reticulum lumen. Unfortunately, little is known about the influence of dietary lipids on PL incorporation into the nascent lipoprotein. Increased stearic, linoleic and arachidonic acids into TRL PL after the intake of HOSO compared with VOO has been reported $^{24}$. Now we also show that minor components contained in VOO may affect the incorporation of preformed PL to postprandial TRL, which may have important consequences on TRL hydrolysis in the bloodstream, as the PL monolayer needs to be crossed by the lipolytic enzymes to reach the TAG core, and on TRL uptake by the liver.

Incubation of hepatocytes with particles obtained after consumption of HOSO as compared to VOO and EVO induced lower intracellular TAG accumulation, but also lower TAG and CE secretion in the form of VLDL in the case of EVO. The lower lipid accumulation and secretion must be due to less TRL uptake by the cells and/or a higher rate of intracellular metabolism. Since a previous study from our laboratory has suggested that HOSO TRL are taken up by hepatocytes more rapidly that VOO or EVO TRL ${ }^{15}$, probably due to upregulation of the LDL receptor-related protein, we conclude that TAG delivered to the liver by HOSO TRL are not directed to re-secretion in VLDL, and are probably more rapidly metabolized by $\beta$-oxidation of the fatty acids. Hepatic mRNA expression for DGAT, apoB and MTP, key proteins involved in VLDL synthesis and secretion, were induced above control concentrations to a greater extent after incubation with HOSO TRL compared with the other dietary 
oils. Interestingly, the effects of the TRL on the expression of mRNA for these proteins appeared to be inversely related to those on VLDL lipid secretion, with HOSO TRL-treated cells generally showing the highest mRNA concentrations, but the lowest secretion of TAG and CE.

The different TRL types also had differential effects on the expression of mRNA for PPAR $\alpha$, a nuclear transcription factor known to play a role in regulating the expression of genes involved in VLDL synthesis and secretion ${ }^{25}$. HOSO TRL was found to increase the abundance of mRNA for PPAR $\alpha$ in comparison to EVO TRL and VOO TRL. Increased PPAR $\alpha$ mRNA expression coupled with lower TAG secretion in VLDL have also been reported by Linden et al. ${ }^{25}$, who showed that activation of PPAR $\alpha$ gives rise to the synthesis of smaller VLDL particles by rat hepatocytes so that lipid secretion was decreased. As well as the size and lipid load of the secreted VLDL, the expression of MTP gene expression and apoB synthesis are also regulated by PPAR $\alpha^{25,26}$. It is possible, therefore that the down-regulation of the expression of mRNA for DGAT, apoB and MTP observed with EVO TRL as compared to HOSO TRL may be due to decreased PPAR $\alpha$ expression, but further work is needed before a definitive conclusion can be drawn.

Increasing the unsaponifiable content of VOO did not exert a significant effect on lipid accumulation in rat primary hepatocytes and/or on VLDL secretion, despite the differences found in the PL fatty acid composition of VOO TRL and EVO TRL. Nevertheless, EVO showed a tendency to limit the effect of VOO against HOSO. Although the differences did not reach significance, values for VLDL lipid composition and mRNA in hepatocytes were almost always intermediate between those obtained after the intake of HOSO and VOO. This indicates that supplementing VOO with the unsaponifiable fraction does not exacerbate the effect of VOO but, in contrast, it appears to limit it.

In summary, consumption of a meal containing HOSO or VOO, which contain similar high concentrations of oleic acid, but differ in their minor components, leads to the production of TRL with markedly different lipid compositions, which have differential effects on hepatic lipid metabolism. Incubation of TRL obtained after HOSO intake led to lower intracellular lipid accumulation in primary rat hepatocytes, but also to a lower secretion of lipid in VLDL from these cells, compared with VOO and EVO TRL. This was concomitant to higher mRNA expression for proteins related to the lipid synthesis and VLDL assembly (DGAT, MTP and apoB). These apparently contradictory changes may possibly be due to the down-regulation of $\operatorname{PPAR} \alpha$ expression in VOO TRL as compared to HOSO TRL-treated cells, since activation of PPAR $\alpha$ is associated with the secretion of lipid-depleted VLDL ${ }^{26}$. This has important implications with regard to the influence of high-oleic acid dietary oils in modulating the risk of CVD, since it has been demonstrated that secretion of lipid-depleted VLDL promotes the rapid formation of atherogenic $\mathrm{LDL}^{27}$. Since HOSO and VOO contain similar high concentrations of oleic acid, their different effects on VLDL secretion can be attributed to the differences in their minor components. Supplementation of VOO with its own unsaponifiable fraction, however, had only minor effects on the lipid composition of postprandial TRL and did not change their influence on hepatocyte lipid content or VLDL lipid secretion, although it did limit the differential effects of VOO and HOSO on hepatic lipid metabolism.

\section{Acknowledgements}

This work was supported by funds from Comision Interministerial de Ciencia y Tecnologia (CYCIT, AGL2005-00 572), Fondo de Investigaciones Sanitarias (FIS. Red Corporativa ISCIII G03/ 140-2002) and a Juan de la Cierva contract to J. S. P.

\section{References}

1. Redgrave TG (1983) Formation and metabolism of chylomicrons. Int Rev Physiol 28, 103-130.

2. Mamo JC \& Wheeler JR (1994) Chylomicrons or their remnants penetrate rabbit thoracic aorta as efficiently as do smaller macromolecules, including low-density lipoprotein, high-density lipoprotein, and albumin. Coron Artery Dis 5, 695-705.

3. Grieve DJ, Avella MA, Elliott J \& Botham KM (1998) The influence of chylomicron remnants on endothelial cell function in the isolated perfused rat aorta. Atherosclerosis 139, 273-281.

4. Napolitano M, Avella M, Botham KM \& Bravo E (2003) Chylomicron remnant induction of lipid accumulation in $\mathbf{J 7 7 4}$ macrophages is associated with up-regulation of triacylglycerol synthesis which is not dependent on oxidation of the particles. Biochim Biophys Acta 1631, 255-264.

5. Batt KV, Avella M, Moore EH, Jackson B, Suckling KE \& Botham KM (2004) Differential effects of low-density lipoprotein and chylomicron remnants on lipid accumulation in human macrophages. Exp Biol Med (Maywood) 229, 528-537.

6. Wang CS, Hartsuck J \& McConathy WJ (1992) Structure and functional properties of lipoprotein lipase. Biochim Biophys Acta 1123, 1-17.

7. Zeng BJ, Mortimer BC, Martins IJ, Seydel U \& Redgrave TG (1998) Chylomicron remnant uptake is regulated by the expression and function of heparan sulfate proteoglycan in hepatocytes. J Lipid Res 39, 845-860.

8. Rohlmann A, Gotthardt M, Hammer RE \& Herz J (1998) Inducible inactivation of hepatic LRP gene by cre-mediated recombination confirms role of LRP in clearance of chylomicron remnants. J Clin Invest 101, 689-695.

9. Lambert MS, Avella MA, Berhane Y, Shervill E \& Botham KM (2001) The fatty acid composition of chylomicron remnants influences their binding and internalization by isolated hepatocytes. Eur J Biochem 268, 3983-3992.

10. Zheng X, Avella M \& Botham KM (2001) Comparison of the effects of dietary n-3 and n- 6 polyunsaturated fatty acids on very-low-density lipoprotein secretion when delivered to hepatocytes in chylomicron remnants. Biochem J 357, 481-487.

11. Gibbons GF, Wiggins D, Brown AM \& Hebbachi AM (2004) Synthesis and function of hepatic very-low-density lipoprotein. Biochem Soc Trans 32, 59-64.

12. Keys A, Menotti A, Karvonen MJ, et al. (1986) The diet and 15year death rate in the seven countries study. Am J Epidemiol 124, 903-915.

13. Abia R, Pacheco YM, Perona JS, Montero E, Muriana FJ \& Ruiz-Gutierrez V (2001) The metabolic availability of dietary triacylglycerols from two high oleic oils during the postprandial period does not depend on the amount of oleic acid ingested by healthy men. J Nutr 131, 59-65.

14. Perona JS, Martinez-Gonzalez J, Sanchez-Dominguez JM, Badimon L \& Ruiz-Gutierrez V (2004) The unsaponifiable fraction of virgin olive oil in chylomicrons from men improves the balance between vasoprotective and prothrombotic factors released by endothelial cells. J Nutr 134, 3284-3289. 
15. Perona JS, Avella M, Botham KM \& Ruiz-Gutierrez V (2006) Uptake of triacylglycerol-rich lipoproteins of differing triacylglycerol molecular species and unsaponifiable content by liver cells. Br J Nutr 95, 889-897.

16. Ruiz-Gutierrez V, Perona JS, Pacheco YM, Muriana FJ \& Villar J (1999) Incorporation of dietary triacylglycerols from olive oil and high-oleic sunflower oil into VLDL triacylglycerols of hypertensive patients. Eur J Clin Nutr 53, 687-693.

17. Folch J, Lees M \& Sloane-Stanley GH (1957) A simple method for the isolation and purification of total lipids from animal tissues. J Biol Chem 226, 497-509.

18. Perona JS \& Ruiz-Gutierrez V (2004) Quantification of major lipid classes in human triacylglycerol-rich lipoproteins by high-performance liquid chromatography with evaporative light-scattering detection. J Sep Sci 27, 653-659.

19. Ruiz-Gutierrez V, Montero E \& Villar J (1992) Determination of fatty acid and triacylglycerol composition of human adipose tissue. J Chromatogr 581, 171-178.

20. Perona JS \& Ruiz-Gutiérrez V (1999) Characterization of the triacylglycerol molecular species of fish oil by reversed-phase high-performance liquid chromatography. J Liquid Chromatogr Rel Technol 22, 1699-1714.

21. Ford RP, Botham KM, Suckling KE \& Boyd GS (1985) The effect of a rat plasma high-density lipoprotein subfraction on the synthesis of bile salts by rat hepatocyte monolayers. FEBS Lett 179, 177-180.
22. Isusi E, Aspichueta P, Liza M, Hernandez ML, Diaz C, Hernandez G, Martinez MJ \& Ochoa B (2000) Short- and long-term effects of atorvastatin, lovastatin and simvastatin on the cellular metabolism of cholesteryl esters and VLDL secretion in rat hepatocytes. Atherosclerosis 153, 283-294.

23. Hussain M (2000) A proposed model for the assembly of chylomicrons. Atherosclerosis 148, 1-15.

24. Abia R, Pacheco YM, Montero E, Ruiz-Gutierrez V \& Muriana FJ (2003) Distribution of fatty acids from dietary oils into phospholipid classes of triacylglycerol-rich lipoproteins in healthy subjects. Life Sci 72, 1643-1654.

25. Linden D, Lindberg K, Oscarsson J, Claesson C, Asp L, Li L, Gustafsson M, Boren J \& Olofsson SO (2002) Influence of peroxisome proliferator-activated receptor alpha agonists on the intracellular turnover and secretion of apolipoprotein (Apo) B-100 and ApoB-48. J Biol Chem 277, 23044-23053.

26. Ameen C, Edvardsson U, Ljungberg A, Asp L, Akerblad P, Tuneld A, Olofsson SO, Linden D \& Oscarsson J (2005) Activation of peroxisome proliferator-activated receptor alpha increases the expression and activity of microsomal triglyceride transfer protein in the liver. J Biol Chem 280, 1224-1229.

27. Packard CJ, Munro A, Lorimer AR, Gotto AM \& Shepherd J (1984) Metabolism of apolipoprotein B in large triglyceriderich very low density lipoproteins of normal and hypertriglyceridemic subjects. J Clin Invest 74, 2178-2192. 